\title{
The impact of oxidation on spore and pollen chemistry
}

\author{
PHILLIP E. JARDINE ${ }^{*}$, WESLEY T. FRASER ${ }^{1,2}$, BARRY H. LOMAX $^{3}$ \& WILLIAM D. GOSLING ${ }^{1,4}$ \\ ${ }^{1}$ Department of Environment, Earth and Ecosystems, The Open University, Milton Keynes MK7 6AA, UK \\ ${ }^{2}$ Geography, Department of Social Sciences, Oxford Brookes University, Oxford OX3 0BP, UK \\ ${ }^{3}$ Agriculture and Environmental Science, University of Nottingham, Sutton Bonington Campus, Leicestershire LE12 5RD, UK \\ ${ }^{4}$ Palaeoecology \& Landscape Ecology, Institute of Biodiversity \& Ecosystem Dynamics (IBED), University of Amsterdam, \\ 1090 GE Amsterdam, The Netherlands \\ *Corresponding author (email: phillip.jardine@open.ac.uk)
}

\begin{abstract}
Sporomorphs (pollen and spores) have an outer wall composed of sporopollenin. Sporopollenin chemistry contains both a signature of ambient ultraviolet-B flux and taxonomic information, but it is currently unknown how sensitive this is to standard palynological processing techniques. Oxidation in particular is known to cause physical degradation to sporomorphs, and it is expected that this should have a concordant impact on sporopollenin chemistry. Here, we test this by experimentally oxidizing Lycopodium (clubmoss) spores using two common oxidation techniques: acetolysis and nitric acid. We also carry out acetolysis on eight angiosperm (flowering plant) taxa to test the generality of our results. Using Fourier Transform infrared (FTIR) spectroscopy, we find that acetolysis removes labile, non-fossilizable components of sporomorphs, but has a limited impact upon the chemistry of sporopollenin under normal processing durations. Nitric acid is more aggressive and does break down sporopollenin and reorganize its chemical structure, but when limited to short treatments (i.e. $\leq 10 \mathrm{~min}$ ) at room temperature sporomorphs still contain most of the original chemical signal. These findings suggest that when used carefully oxidation does not adversely affect sporopollenin chemistry, and that palaeoclimatic and taxonomic signatures contained within the sporomorph wall are recoverable from standard palynological preparations.
\end{abstract}

KEYWORDS: oxidation, palynology, ultraviolet-B, FTIR, sporopollenin

SUPPLEMENTARY MATERIAL: R code for all analyses, the complete dataset and additional figures are available at http://www.geolsoc.org.uk/SUP18811

Gold Open Access: this article is published under the terms of the CC-BY 3.0 license.

\section{INTRODUCTION}

Sporomorphs (pollen and spores) are the reproductive vectors of land plants. The outer sporomorph wall, or exine, is formed of a highly durable biopolymer called sporopollenin (Brooks \& Shaw, 1968, 1978; Ariizumi \& Toriyama, 2011). Sporopollenin is resistant to physical, biological and chemical attack, providing sporomorphs with a high preservation potential and an abundant fossil record that extends to the colonization of the land by plants in the Ordovician c. $470 \mathrm{Ma}$ (Rubenstein et al., 2010). The study and use of sporomorphs has traditionally been linked to taxonomy based on the morphology of the individual grains (von Post, 1916; Traverse, 1988). Recent studies have demonstrated the utility of exine chemistry, both as an indicator of past ultraviolet-B flux (Rozema et al., 1999, 2001a, 2001b; Rozema, 2002; Blokker et al., 2005; Watson et al., 2007; Lomax et al., 2008, 2012; Fraser et al., 2011, 2014a; Willis et al., 2011) and as a taxonomic tool in palynology (Pappas et al., 2003; Dell'Anna et al., 2009; Steemans et al., 2010; Zimmermann, 2010). The chemical composition of sporopollenin is evolutionarily highly conserved (Fraser et al., 2012), making exine chemistry a potentially useful tool over extended geological time-scales (Fraser et al., 2014a).

Despite being highly resistant, sporopollenin is susceptible to oxidation, which will degrade and destroy sporomorphs that remain in oxic environments for long periods (Havinga, 1984; Traverse, 1988; Twiddle \& Bunting, 2010); however, oxidation is a necessary stage in standard sporomorph processing procedures (Traverse, 1988; Faegri \& Iversen, 1989; Wood et al., 1996). Oxidation is used to remove extraneous organic debris such as cellulose and plant tissue, which would otherwise decrease sporomorph concentrations and obscure grains, hindering identification and counting. Naturally, oxidative treatments have to be mild and short enough to limit damage to the sporomorphs themselves. Two methods of oxidation that are commonly used in fossil pollen preparation are acetolysis and treatment with nitric acid (Traverse, 1988; Faegri \& Iversen, 1989; Wood et al., 1996). Both types of oxidation can be carried out at room temperature, but heating is often used in the preparations to accelerate and intensify the oxidation process (Wood et al., 1996).

Acetolysis, using a mix of acetic anhydride $\left(\left[\mathrm{CH}_{3} \mathrm{CO}\right]_{2} \mathrm{O}\right)$ and sulphuric acid $\left(\mathrm{H}_{2} \mathrm{SO}_{4}\right)$, is used in Quaternary and Recent palynology where unconsolidated sediment samples (Faegri \& Iversen, 1989), pollen traps (Gosling et al., 2003) and honey (Lieux, 1980) are processed. Acetolysis is also frequently used when preparing sporomorphs harvested directly from modern plant specimens, to remove the cellular protoplasm, the cellulose-based inner pollen wall (intine) and outer proteins and lipids, and thus increase the clarity of exinal structural features that are present in fossil specimens (Traverse, 1988). Stronger oxidizing agents, such as nitric acid $\left(\mathrm{HNO}_{3}\right)$ and Schulze's reagent (a mixture of $\mathrm{HNO}_{3}$ and potassium chlorate $\left[\mathrm{KClO}_{3}\right]$ ), are typically used when processing rock samples (Traverse, 1988; Wood et al., 1996), where the 


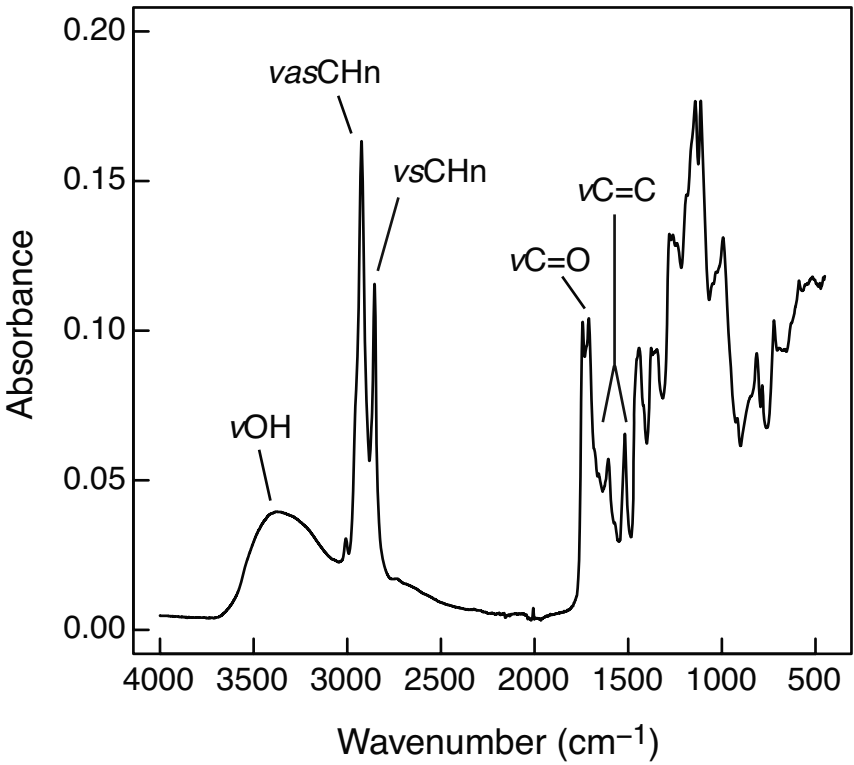

Fig. 1. FTIR spectrum for unoxidized Lycopodium spores, showing interpretation of spectral absorbance peaks.

dispersed organic matter has undergone diagenetic changes during post-burial compaction and/or thermal maturation.

The physical effects of oxidative treatments on sporomorphs are well known: initial darkening of the exine, increased size, degradation and, in time, destruction (Johnson 1985; Traverse, 1988; Wood et al., 1996; Lebreton et al., 2010). However, there is currently much less of an understanding of how oxidation affects sporomorph chemistry, and what this means for recovering information on UV-B flux and plant taxonomy from standard palynological preparations, and from fossil sporomorphs that have undergone natural oxidation prior to burial. Previous studies (Hemsley et al., 1996; Rozema et al., 2001a; Blokker et al., 2005) have demonstrated a decline in the concentration of aromatic compounds (including UV-B absorbing phenolic compounds) in sporomorphs following oxidation. However, it is not clear if these chemical changes represent alteration of the exine or simply loss of the protoplasm, intine and outer compounds, or whether different oxidation methods affect sporomorph and sporopollenin chemistry in similar ways, and these questions are yet to be comprehensively addressed in a rigorous experimental framework.

In this study we test the impact of oxidation on sporopollenin chemistry by experimentally oxidizing Lycopodium (clubmoss) spores with both acetolysis and nitric acid, at room temperature and at $90^{\circ} \mathrm{C}$, and over a range of durations from one minute to four hours. We use Fourier transform infrared (FTIR) spectroscopy to characterize changes in sporopollenin chemistry, and contrast these with the physical impacts of oxidation that can be observed during routine palynological analysis.

\section{MATERIALS AND METHODS}

Oxidation experiments were carried out on Lycopodium spores sourced from Sigma-Aldrich Co., which comprise a mix of different Lycopodium species. For all treatments $2.3 \mathrm{ml}$ of oxidizing agent was added to $0.2 \mathrm{ml}$ of dry Lycopodium spores. To test the effect of the oxidizing agents over different durations, we oxidized samples for $1,2,3,5,10,30,60,120$ and $240 \mathrm{~min}$, with 6 replicates per time interval. Treatments were run both at room temperature, and at $90^{\circ} \mathrm{C}$ in a water bath.

For treatments with acetolysis, nine parts acetic anhydride $\left(\left[\mathrm{CH}_{3} \mathrm{CO}\right]_{2} \mathrm{O}\right)$ was mixed with one part sulphuric acid $\left(\mathrm{H}_{2} \mathrm{SO}_{4}\right)$ to produce the acetolysizing agent (Faegri \& Iversen, 1989). After the designated time interval, the centrifuge tubes were topped up with glacial acetic acid $\left(\mathrm{CH}_{3} \mathrm{COOH}\right)$ to stop the reaction, and then centrifuged for $10 \mathrm{~min}$ and the supernatant decanted. The centrifuge tubes were then topped up with water, centrifuged and decanted twice more. For treatments with nitric acid $\left(\mathrm{HNO}_{3}\right), 70 \%$ nitric acid was used. The centrifuge tube was topped up with water to stop the reaction, centrifuged for $10 \mathrm{~min}$ and the supernatant decanted. As with the acetolysis treatments, the samples were then topped up with water and centrifuged twice, to remove the remaining acid. The samples were then air-dried for IR analysis.

In addition to the oxidized treatments, two controls were used, each with six replicates. Untreated spores were used to observe the initial chemical state of the sporopollenin. To replicate previous analyses on modern material with FTIR (e.g. Lomax et al., 2008; Fraser et al., 2011) we also treated a set of replicates with acetone $\left(\left[\mathrm{CH}_{3}\right]_{2} \mathrm{CO}\right)$, washing the sample and removing the supernatant four times, and allowing the samples to air dry. In total we produced 228 samples for chemical analysis (two oxidizing agents $\times$ two heat levels $\times$ nine time intervals $\times$ six replicates, plus the 12 control samples).

One replicate from each treatment was examined under a microscope and photographed to compare physical and chemical changes across treatments. Photographs were taken using a QImaging MicroPublisher 3.3 RTV camera attached to a Nikon Eclipse 50i microscope, under plain light and at $400 \times$ magnification.

IR spectra (Fig. 1) were generated on a PerkinElmer (Seer Green, Buckinghamshire, UK) Spectrum Two IR spectrometer, with a diamond cell ATR Two accessory. Spectra were collected using the PerkinElmer Spectrum software at 16 scans per sample. Background spectra were collected prior to each set of six replicates and automatically subtracted from each replicate. We analysed the spectra in two ways: with principal components analysis (PCA), and by measuring peak height ratios across treatments. PCA is an ordination technique that finds axes of maximum variation within the dataset, and thereby allows most of the variation within the dataset to be expressed in a minimal number of dimensions (Varmuza \& Filzmoser, 2009). It is therefore a convenient way of comparing whole spectra from multiple samples. Prior to running the PCA, each spectrum was standardized to a zero mean and unit variance, by subtracting the mean value and dividing by the standard deviation (Duarte et al., 2004). This removes the effect of sample thickness on the absorbance spectra.

Peak heights, corresponding to specific functional groups, were measured using ThermoFisher TQ analyst software, relative to a linear baseline tied to each spectrum at 1900 and $3800 \mathrm{~cm}^{-1}$. Peaks were measured as the maximum value in a predefined interval (Table 1) to allow for small movements in the position of the peaks on the absorbance spectra. We use ratios between peak heights to characterize sporopollenin chemistry, again to remove the potential impact of differing sample thickness on absolute absorbance values. UV-B absorbing compounds are detected in IR spectra via an absorbance peak that occurs near $1510 \mathrm{~cm}^{-1}$, caused by the stretching 
Table 1. Band assignments of absorbance bands used in ratios.

\begin{tabular}{lccc}
\hline Wavenumber $\left(\mathrm{cm}^{-1}\right)$ & Measurement interval & Band assignment & Functional group \\
\hline 3300 & 3190,3550 & $v \mathrm{OH}$ & Hydroxyl \\
2925 & 2915,2930 & vas $\mathrm{CHn}$ & Aliphatic \\
1710 & 1700,1720 & $v \mathrm{C}=\mathrm{O}$ & Carboxyl \\
1600 & 1595,1620 & $v \mathrm{C}=\mathrm{C}$ & Aromatic $^{\mathrm{a}}$ \\
1510 & 1505,1525 & $v \mathrm{C}=\mathrm{C}$ & Aromatic $^{\mathrm{b}}$ \\
\hline
\end{tabular}

Measurement interval is the interval within which each band height was measured, taken as the maximum value within that interval. Band assignments follow Watson et al. (2007) and Fraser et al. (2011, 2014b). $v=$ stretching; as = asymmetrical.

of $\mathrm{C}=\mathrm{C}$ bonds in the aromatic ring structure (Watson et al., 2007; Fraser et al., 2014b), and have previously been quantified via a ratio with the broad hydroxyl absorbance band that centres on $3300 \mathrm{~cm}^{-1}$ (Fig. 1) (Lomax et al., 2008, 2012; Fraser et al., 2011). Following Steemans et al. (2010) and Fraser et al. (2014b), we also examine a number of other peak height ratios that provide direct information on the balance among aliphatic, aromatic and carboxyl functional groups. Specifically, we focus on the following ratios (Table 1, Fig. 1): aliphatic (vas CHn, $\left.2925 \mathrm{~cm}^{-1}\right) /$ aromatic $^{\mathrm{a}}$ $\left(v \mathrm{C}=\mathrm{C}, 1600 \mathrm{~cm}^{-1}\right)$, aliphatic $\left(\right.$ vas $\left.\mathrm{CHn}, 2925 \mathrm{~cm}^{-1}\right) / \operatorname{aromatic}^{\mathrm{b}}(v \mathrm{C}=\mathrm{C}$, $\left.1510 \mathrm{~cm}^{-1}\right)$, aliphatic (vas $\left.\mathrm{CHn}, 2925 \mathrm{~cm}^{-1}\right) /$ carboxyl $\quad(v \mathrm{C}=\mathrm{O}$, $\left.1710 \mathrm{~cm}^{-1}\right)$, and carboxyl $\left(v \mathrm{C}=\mathrm{O}, 1710 \mathrm{~cm}^{-1}\right) /$ aromatic $^{\mathrm{a}} \quad(v \mathrm{C}=\mathrm{C}$, $\left.1600 \mathrm{~cm}^{-1}\right)$. A second aliphatic peak at $2850 \mathrm{~cm}^{-1}$ that represents symmetrical stretching of $\mathrm{CHn}$ groups was not included in the ratios, because changes in this peak correspond closely to those in the $2925 \mathrm{~cm}^{-1}$ aliphatic peak (Figs 2 and S1).

To broaden out the relevance of our findings to other taxonomic groups, we conducted a more limited set of oxidation experiments on eight angiosperm (flowering plant) species. These are Artemisia tridentata Nuttall (sagebrush, Asteraceae), Betula fontinalis Sargent (birch, Betulaceae), Iva xanthifolia Nuttall (marshelder, Asteraceae), Juglans nigra Linneaus (walnut, Juglandaceae), Kochia scoparia (Linneaus) Shrader (ragweed, Amaranthaceae), Populus tremuloides Michaux (aspen, Salicaceae), Secale cereale Linneaus (rye, Poaceae), and Sorghum halepense (Linneaus) Persoon (Johnson grass, Poaceae). All were sourced from Sigma-Aldrich. Only acetolysis for $10 \mathrm{~min}$ at $90^{\circ} \mathrm{C}$ was carried out on these taxa, because this is the most extreme treatment that is typical for non-fossil material (e.g. Traverse, 1988); there were no replicate samples. The eight angiosperm taxa were compared with similarly oxidized Lycopodium with both PCA and peak height ratios.

All data analysis was carried out in $\mathrm{R}$ version 3.1.0 ( $\mathrm{R}$ Core Team, 2014). Supporting material for this article is available at http://www.geolsoc.org.uk/SUP18811, and includes R code for all analyses, the complete dataset in Tables S1-S6, and additional figures S1 and S2.

\section{RESULTS}

\section{Physical changes}

Lycopodium spores treated with cold acetolysis do not change obviously with longer durations, and remain similar to the untreated sample (Plate 1). Spores treated with hot acetolysis get progressively darker, and show limited damage to the outer reticulate sculpture after $10 \mathrm{~min}$ of oxidation. By $240 \mathrm{~min}$ the spores are dark brown and fractured, but are still fully recognizable as Lycopodium spores. Some slight increase in spore size (Johnson
1985) may also have occurred, but the statistical significance of this was not investigated. Cold nitric acid turns the spores yellowbrown and, although after $60 \mathrm{~min}$ only limited damage has occurred, by $240 \mathrm{~min}$ the spores have started to break up and combine together, forming more of a gel than a powder. This process occurs much more rapidly with heated nitric acid oxidation, and after just one minute visible damage has started to occur. After two minutes the spores have started to break down completely, and by $10 \mathrm{~min}$ the spore remnants have fully amalgamated. Whereas in the other three oxidation treatments there was no obvious reduction in the quantity of sample remaining, there is a large and immediate decrease with hot nitric acid, and after 60 min only a very thin film remains. There was only sufficient material remaining for study in five of the six replicates for the $60 \mathrm{~min}$ treatment, and not enough in any of the 120 and $240 \mathrm{~min}$ replicates. Results for hot nitric acid therefore only extend to $60 \mathrm{~min}$.

\section{Chemical changes}

Whole spectrum changes. Samples treated with cold acetolysis show only subtle differences to untreated material (Figs 2A and $\mathrm{S} 1)$. There are slight positive and negative shifts in absorbance peaks between 900 and $1300 \mathrm{~cm}^{-1}$ that probably represent $\mathrm{C}-\mathrm{O}$ bonds (Watson et al., 2007), and a slight decrease in the aliphatic peaks at 2925 and $2850 \mathrm{~cm}^{-1}$, but there are no clear trends with increasing treatment durations. Applying heat to the acetolysis treatment (Figs 2B and S1) produces an immediate chemical shift with several peaks decreasing in size, most notably the aliphatic peaks but also the $1710 \mathrm{~cm}^{-1}$ carboxyl peak, the $1510 \mathrm{~cm}^{-1}$ aromatic ${ }^{\mathrm{b}}$ peak, and $\mathrm{C}-\mathrm{O}$ peaks at 1100 and $980 \mathrm{~cm}^{-1}$. Increases in peak height occur at 1230,1175 and $1025 \mathrm{~cm}^{-1}$. The most obvious changes occur within two to three minutes of acetolysis, and progressively longer treatments produce only minor changes relating to a gradual simplification of the IR spectrum (Fig. S1). Oxidizing Lycopodium with cold nitric acid (Figs 2C and S1) also reduces the size of the aliphatic peaks but not to the same extent as hot acetolysis, and there is also a slight decrease in the size of the $3300 \mathrm{~cm}^{-1}$ hydroxyl band. The carboxyl, aromatic ${ }^{\mathrm{a}}$ and aromatic $^{\mathrm{b}}$ peaks all increase in size. Applying heat (Figs 2D and S1) speeds up the chemical changes considerably, with a large increase in both the carboxyl and aromatic $^{b}$ peaks; the aromatic ${ }^{b}$ peak also shifts position to $c .1550 \mathrm{~cm}^{-1}$. The aromatic ${ }^{\mathrm{a}}$ peak disappears completely, and there is a large decrease in the size of the $\mathrm{C}-\mathrm{O}$ peaks at $c .1120$ and $990 \mathrm{~cm}^{-1}$, and an ester peak at $1740 \mathrm{~cm}^{-1}$ (Watson et al., 2007). 
1 minute
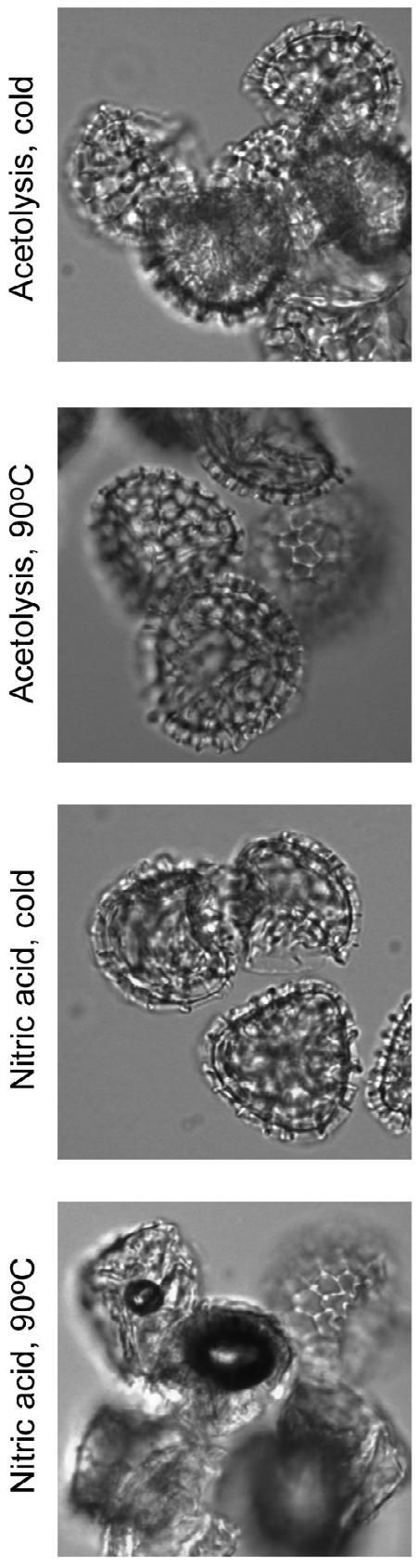

10 minutes
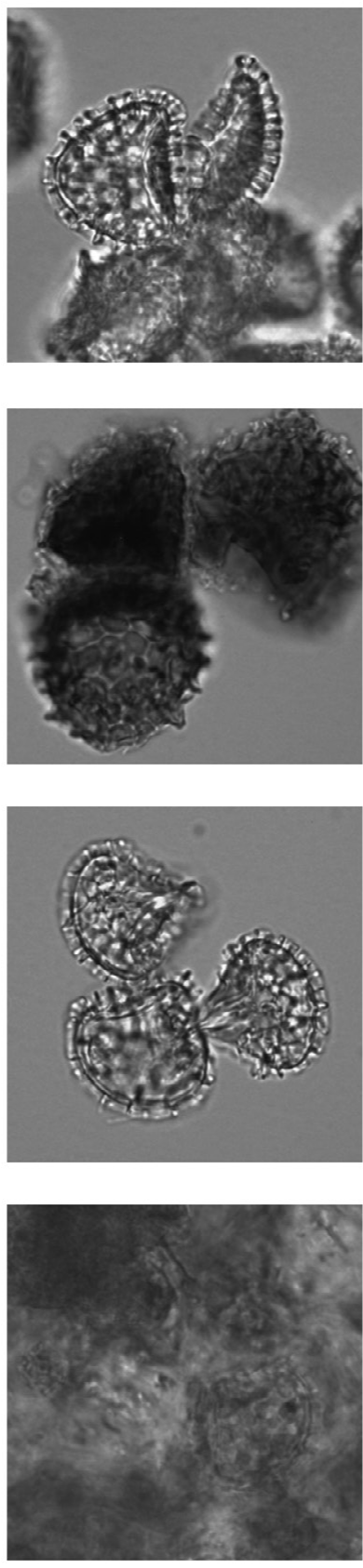

60 minutes
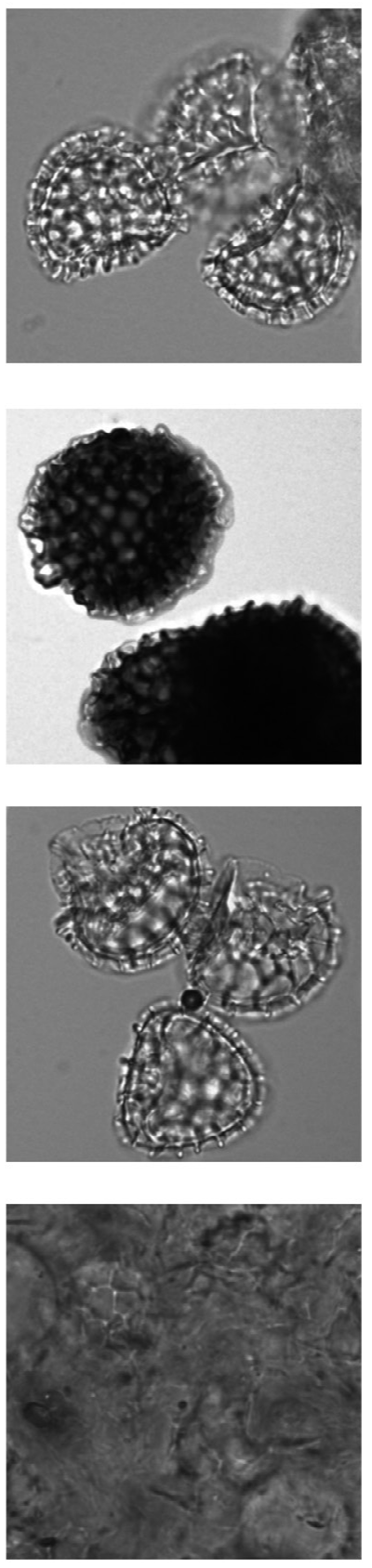

240 minutes
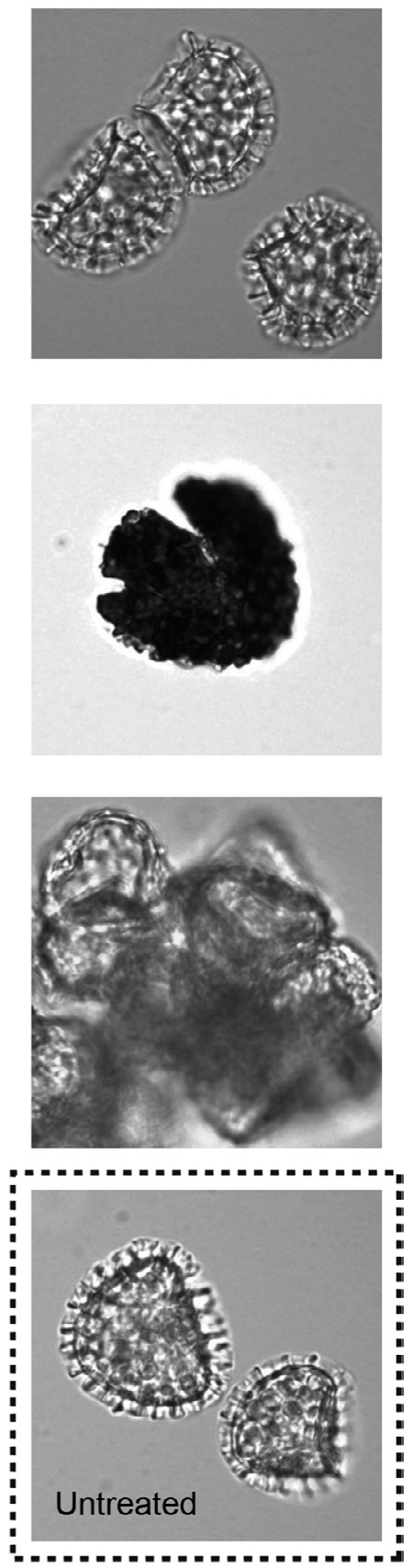

$20 \mu \mathrm{m}$

Explanation of Plate 1. Photomicrographs of Lycopodium spores oxidized using acetolysis and nitric acid at room temperature and at $90^{\circ} \mathrm{C}$, after $1 \mathrm{~min}$, $10 \mathrm{~min}, 60 \mathrm{~min}$ and $240 \mathrm{~min}$. Insufficient material remained after $240 \mathrm{~min}$ of heated nitric acid, the lower right image shows untreated spores for comparison. Photographs taken at $400 \times$ magnification under plain light, scale bar $20 \mu \mathrm{m}$.

The first four PCA axes (Fig. 3) account for $90 \%$ of the total variance in the dataset; further axes were not examined. These four axes reveal clear differences in the IR spectra corresponding to oxidizing agent, temperature and time. Axis 1 (Fig. 3A) accounts for $48 \%$ of the variance in the dataset, and separates out nitric acid from acetolysis and the control samples, most obviously because of the increase in the $1710 \mathrm{~cm}^{-1}$ carboxyl peak and the $1510 \mathrm{~cm}^{-1}$ aromatic ${ }^{b}$ peak (Fig. S2). Axes 2, 3 and 4 respectively account for $23 \%, 12 \%$ and $6 \%$ of variance, and are all associated with both temperature and duration of oxidation. Axis 2 relates to a gradient in the height of the aliphatic peaks (Fig. S2) and there is a clear gradient from cold acetolysis to cold nitric, hot nitric and hot acetolysis, which causes the greatest aliphatic decrease (Fig. 2B). Axes 3 and 4 (Fig. 3B) relate to internal gradients in the nitric and acetolysis samples. 

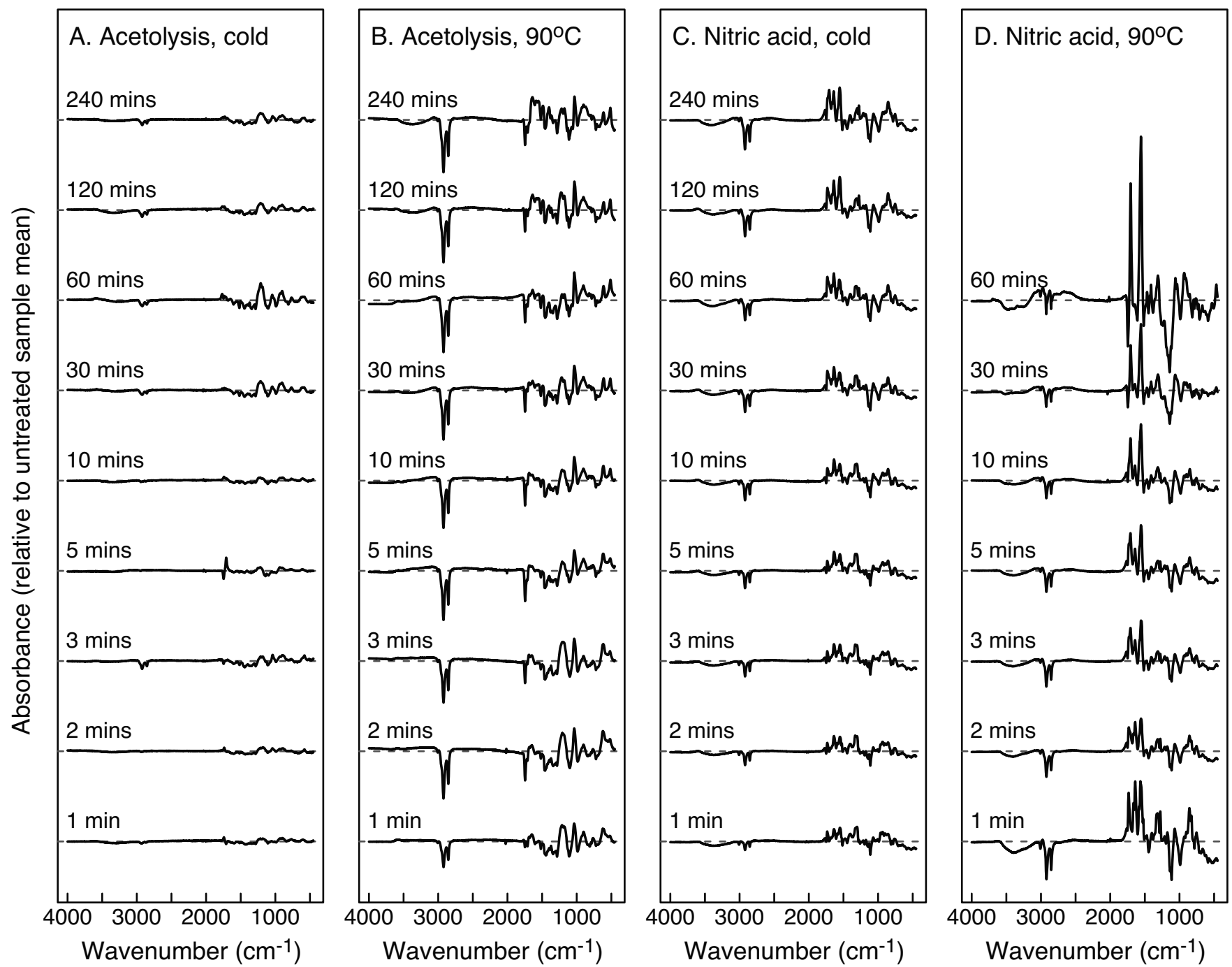

Fig. 2. Difference plots for each oxidation type and duration, showing the mean spectrum minus the mean untreated spectrum. Grey dashed line $=0$ (i.e. no difference between oxidized and untreated spectra). (A) acetolysis at room temperature; (B) acetolysis at $90^{\circ} \mathrm{C}$; (C) nitric acid at room temperature; (D) nitric acid at $90^{\circ} \mathrm{C}$. Note that after $60 \mathrm{~min}$ of oxidation in nitric acid at $90^{\circ} \mathrm{C}$ insufficient material remained to generate IR spectra.

Peak height ratios. The aromatic ${ }^{\mathrm{b}} / \mathrm{hydroxyl}$ ratio (the basis of the UV-B flux proxy) remains similar to the control samples when treated with cold acetolysis, even after 240 min (Fig. 4A). When treated with hot acetolysis (Fig. 4B) there is a reduction to just over $50 \%$ of the untreated ratio after one minute. This remains stable to $10 \mathrm{~min}$ of treatment, but by $30 \mathrm{~min}$ there is a shift to increasing ratio levels. Treatment with cold nitric (Fig. 4C) increases the ratio up until $60 \mathrm{~min}$, after which it decreases. With hot nitric acid (Fig. 4D) the pattern is one of an initial increase at one minute, followed by a gradual decrease, caused by a movement of the aromatic ${ }^{b}$ peak to higher wavenumbers and out of the measurement range (Fig. 2, Table 1). The changes in the aromat$\mathrm{ic}^{\mathrm{b}} /$ hydroxyl ratio are largely down to shifts in the aromatic ${ }^{\mathrm{b}}$ peak height and position; the hydroxyl peak is relatively stable across the treatments (Fig. 2).

For the other ratios that we consider (Fig. 5), treatment with cold acetolysis has very little effect, with no clear trends with increasing durations. Hot acetolysis tends to decrease the size of the ratios quickly, except for the carboxyl/aromatic ${ }^{a}$ ratio which only decreases after 30 min of treatment. Similarly cold nitric acid decreases the ratios except in the case of the carboxyl/aromatic ${ }^{a}$ ratio, which increases with increasing treatment durations. Hot nitric acid speeds this process up so that initial decreases are generally followed by increases above the untreated ratio levels. In most cases, and especially for the shorter durations, there is limited variability among replicates, with oxidation having a consistent impact on the peak height ratios (Fig. 5).

Oxidation and angiosperm pollen. The effect of $10 \mathrm{~min}$ of hot acetolysis is uniform across the eight angiosperm taxa in this study (Fig. 6). In each case there is a slight decrease in the size of the hydroxyl and aliphatic peaks, and at 1075 and $980 \mathrm{~cm}^{-1}$. Large increases occur in the $1710 \mathrm{~cm}^{-1}$ carboxyl peak and at 1230,1175 and $1025 \mathrm{~cm}^{-1}$. Peak height ratios change less in the angiosperm taxa than in the Lycopodium samples (Fig. 7), except in the case 

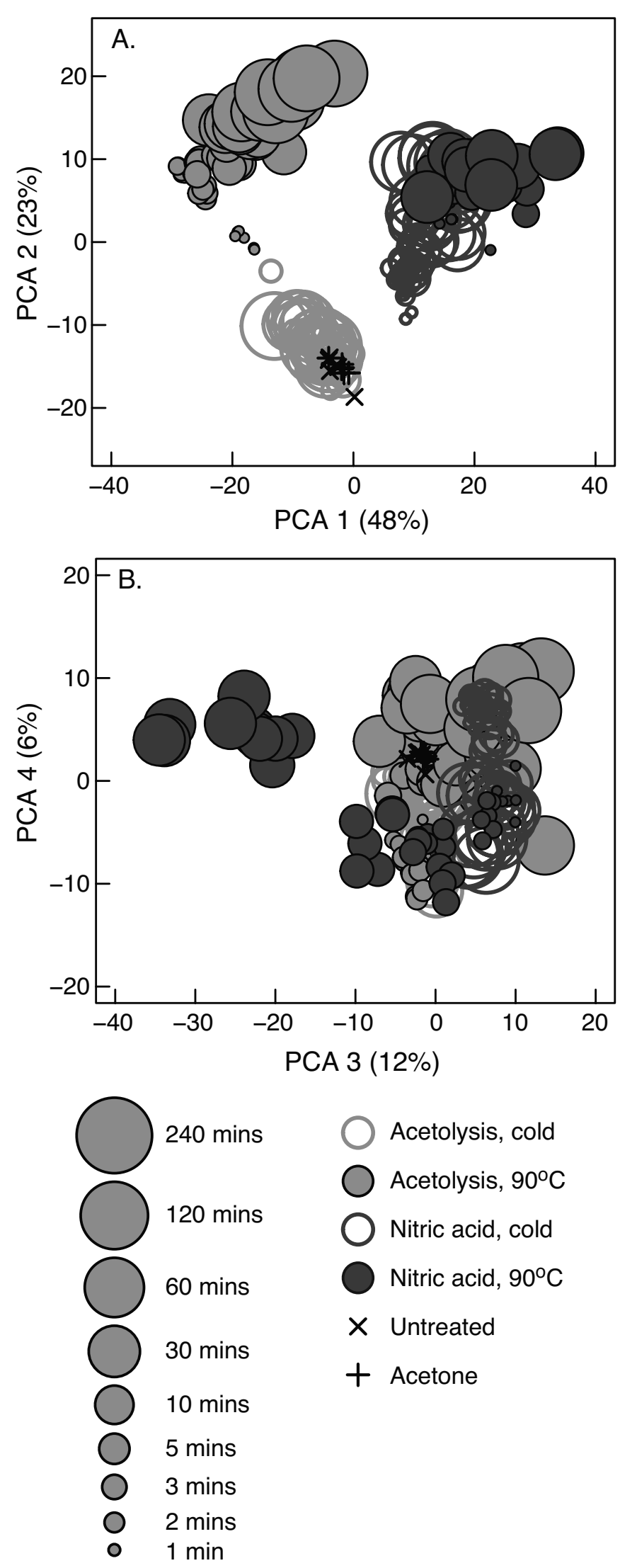

of the carboxyl/aromatic ${ }^{\mathrm{a}}$ and the aliphatic/carboxyl ratios where the pronounced increase in the angiosperm carboxyl peak leads these ratios to increase and decrease, respectively.

A PCA (Fig. 8) of the untreated and acetolysized angiosperm and Lycopodium samples reveals chemical differences related to both oxidation and plant group. The first PCA axis accounts for $58 \%$ of the variance, and separates out the acetolysized (negative scores) from the untreated samples (positive scores), with the angiosperm taxa occurring at either extreme of the axis and the Lycopodium samples being closer to zero. Axis 2 accounts for $23 \%$ of the variation, and shows a clearer differentiation between the acetolysized and untreated Lycopodium samples than is shown on axis 1, and separates out the angiosperm (negative scores) and Lycopodium (positive scores) samples.

\section{DISCUSSION}

These experiments demonstrate that oxidation not only affects the physical nature of sporomorphs, but that the chemical signature is altered both through the isolation of the exine, and through changes to the chemical structure of sporopollenin. These results are therefore important for understanding how sporomorph and sporopollenin chemistry can be used as palaeoclimatic and taxonomic tools under different processing and taphonomic regimes.

Some chemical changes are common across different oxidizing agents and taxonomic groups. The aliphatic peaks decrease consistently, although this occurs most severely with Lycopodium under hot acetolysis. This leads to an overall decrease in peak height ratios (Fig. 5) where the $2925 \mathrm{~cm}^{-1}$ aliphatic peak is the numerator (i.e. aliphatic/carboxyl, aliphatic/aromatic ${ }^{\text {a }}$, aliphatic/ aromatic $^{b}$ ). There are also consistent decreases in $\mathrm{C}-\mathrm{O}$ peaks at 1100 and $980 \mathrm{~cm}^{-1}$, which can probably be related to the loss of the cellulose-based intine (Domínguez et al., 1998). The $1710 \mathrm{~cm}^{-1}$ carboxyl peak decreases in size for Lycopodium under hot acetolysis, but with nitric acid and with the angiosperm taxa this peak increases. While the aromatic ${ }^{b}$ peak at $1510 \mathrm{~cm}^{-1}$ decreases under acetolysis for both Lycopodium and the angiosperm taxa, this peak both increases and shifts to $c$. 1560 wavenumbers with increasing nitric acid treatment (Figs 2 and S1). Domínguez et al. (1998) attributed the presence of new absorbance peaks at c. 1250 and $1050 \mathrm{~cm}^{-1}$ in acetolysized Betula alba pollen to the formation of new $\mathrm{C}-\mathrm{O}$ bonds during acetolysis. Consistent with this, in both Lycopodium and the angiosperm taxa new peaks emerged at 1220, 1175 and $1025 \mathrm{~cm}^{-1}$, although a new peak also appeared at $1060 \mathrm{~cm}^{-1}$ following oxidation with nitric acid.

Treating Lycopodium with acetone produces no obvious chemical change (Figs 3-5), which is consistent with earlier findings by Watson et al. (2007). Similarly, cold acetolysis does very little

Fig. 3. Principal components analysis plots of oxidized Lycopodium samples. (A) PCA axes 1 and 2; (B) PCA axes 3 and 4. Light grey circles denote acetolysized samples; dark grey circles denote samples oxidized with nitric acid; open circles denote oxidation at room temperature; filled circles denote oxidation at $90^{\circ} \mathrm{C}$; diagonal crosses denote untreated samples; vertical crosses denote samples treated with acetone. Size of circles is proportional to length of treatment. Percentages in parentheses are the percentage of variation in the data explained by each PCA axis. 

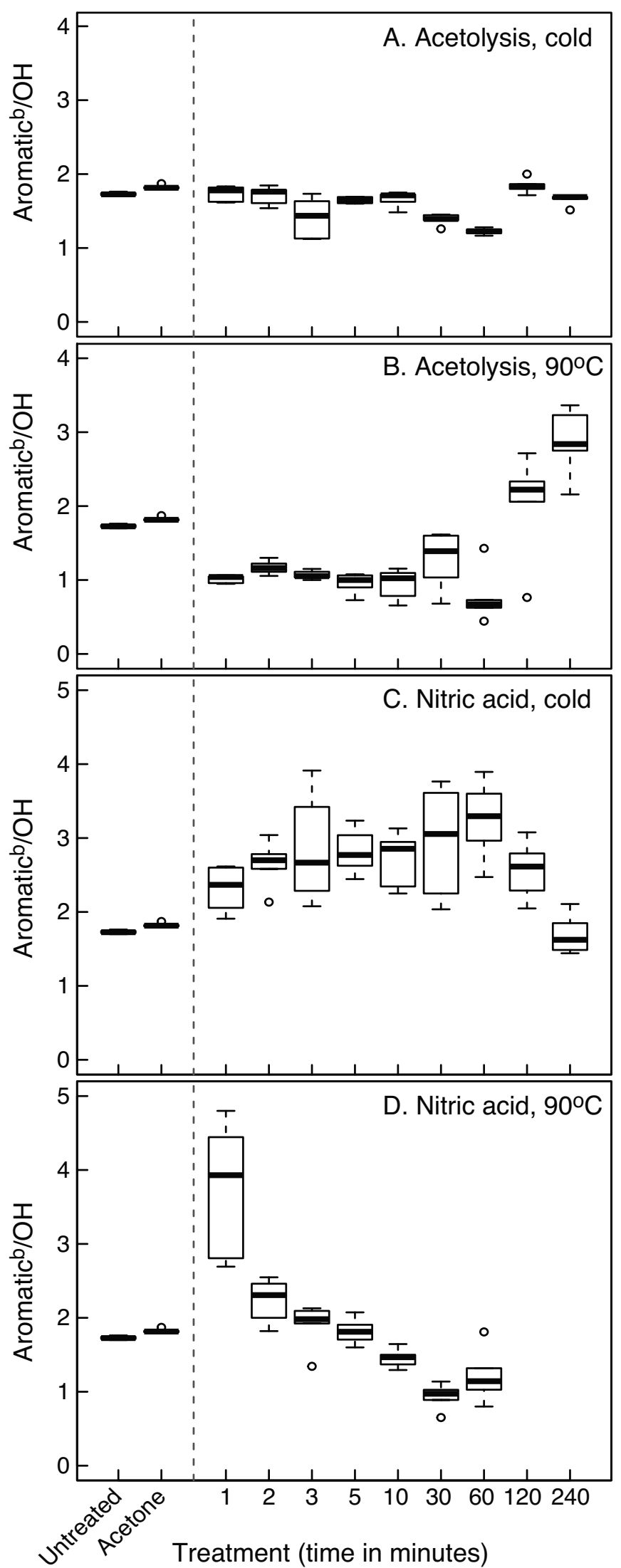

to sporomorph chemistry, suggesting that these two approaches do not strip out the labile, non-exine components, such as the protoplasm and intine, and leave the exine unaltered. Chemical changes observed during hot acetolysis are consistent with the removal of the protoplasm, intine and outer compounds, but with a limited impact upon the chemistry of the exine itself. This is shown by a rapid change in chemistry, including the loss of the cellulose $\mathrm{C}-\mathrm{O}$ peaks, in the first few minutes of acetolysis (Figs 2 and 3), during which the exine is isolated, after which only subtle modifications occur even up to four hours of treatment. Physical degradation of the exine is also limited with acetolysized grains (Plate 1), with noticeable changes only occurring at the longest treatment durations.

Oxidation with nitric acid produces a more significant change in spore appearance and chemistry than acetolysis (e.g. Fig. 3), but this is to be expected given that undiluted nitric acid is a much more aggressive oxidizing agent (Faegri \& Iversen, 1989). As with acetolysis, nitric acid strips out the cellulose and isolates the exine, but in contrast to acetolysis chemical alterations continue to take place with increasing treatment lengths. This suggests fundamental changes in sporopollenin chemistry, which are accompanied by physical degradation and, with sufficient time, disintegration of the exine. Applying heat to oxidation speeds up these changes, and samples treated for over an hour with cold nitric acid chemically and physically resemble those that have been in hot nitric acid for just a few minutes.

These results have clear implications for both reconstructing ultraviolet irradiance in the past, and using sporomorph chemistry as a taxonomic tool. For reconstructing UV-B flux, oxidation removes UV-B absorbing compounds (UACs) that are present in the protoplasm and bound to the exine, reducing the concentration to those that are present in the exine itself (Rozema et al., 2001a; Blokker et al., 2005). Rozema et al. (2001a) estimated that 57\% of UV-B absorbance in Helleborus foetidus pollen occurs in the exine; in Betula pendula $41 \%$ occurs in the exine. In both cases the majority of the remainder of UV-B absorbance occurs in protoplasm UACs. In a study of Alnus glutinosa pollen, Blokker et al. (2005) found that c. $25 \%$ of the concentration of para-coumaric acid was in the exine, and c. $8 \%$ of the ferulic acid concentration. Our experiments on Lycopodium spores show that acetolysis efficiently strips out non-exine phenolic elements, halving the size of the aromatic ${ }^{b} /$ hydroxyl ratio (Fig. 4), but suggest that under normal treatment durations of $1-10 \mathrm{~min}$ (Traverse, 1988; Faegri \& Iversen, 1989) the exine itself is largely unaffected. Acetolysis used in standard Quaternary palynomorph preparations should therefore make no difference to palaeo-UV-B flux reconstructions, because typically only the exine remains in the fossil record (Traverse, 1988) and treatment durations are short

Fig. 4. Box plots of the aromatic $/ \mathrm{OH}\left(=1510 / 3300 \mathrm{~cm}^{-1}\right)$ peak height ratio for each oxidation type and duration. For each group of samples the thick horizontal line shows the median, the ends of the box show the lower and upper quartiles, the whiskers show the extremes of the data up to 1.5 times the interquartile range, and individual data points show any outliers beyond this. (A) Acetolysis at room temperature; (B) acetolysis at $90^{\circ} \mathrm{C} ;(\mathrm{C})$ nitric acid at room temperature; (D) nitric acid at $90^{\circ} \mathrm{C}$. In each case the untreated and acetone samples are shown for comparison. 


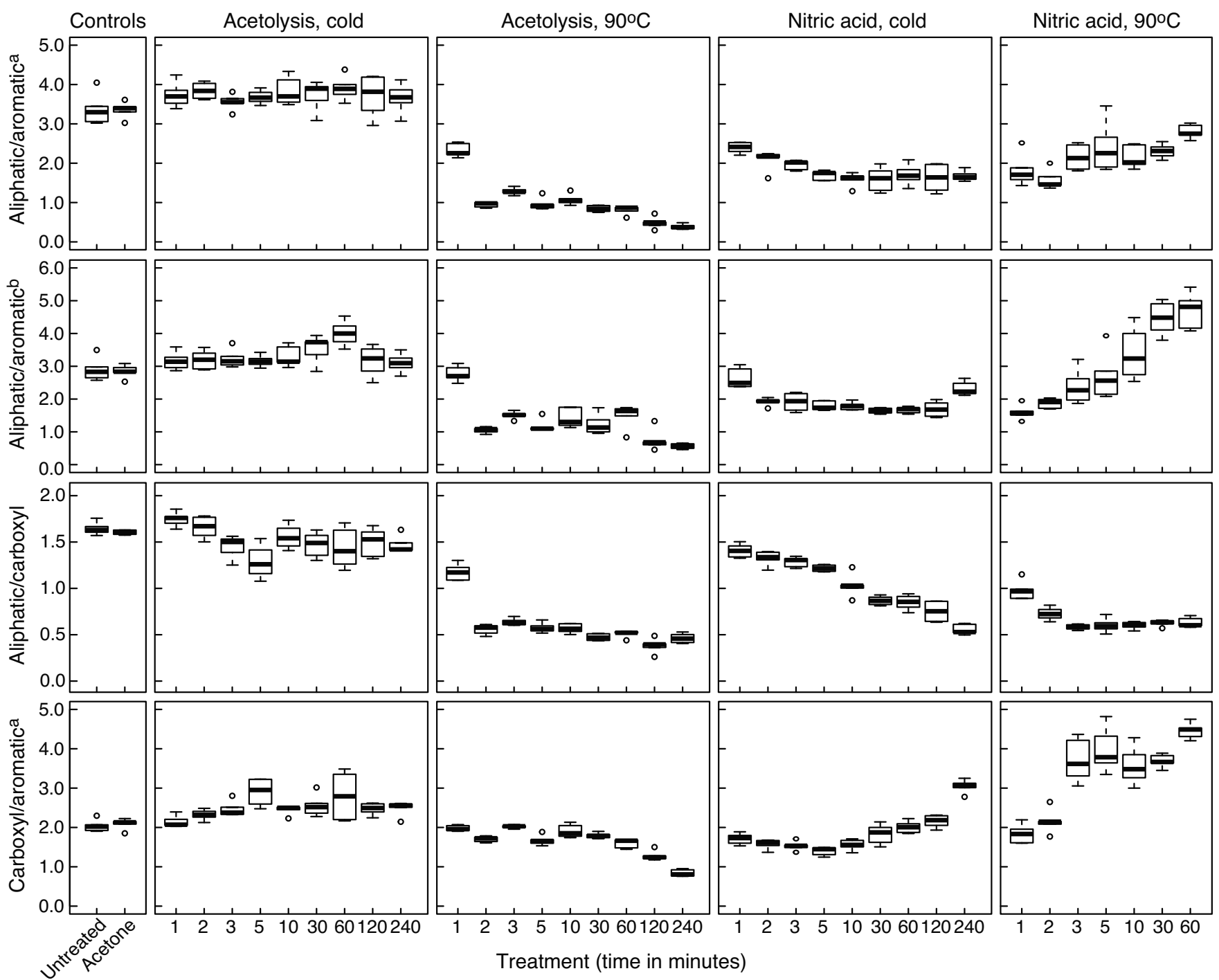

Fig. 5. Box plots of peak height ratios between aliphatic, aromatic and carboxyl peaks, for each oxidation type and duration. First row, aliphatic/ aromatic $^{\mathrm{a}}\left(=2925 / 1600 \mathrm{~cm}^{-1}\right)$ ratio; second row aliphatic/aromatic ${ }^{\mathrm{b}}\left(=2925 / 1510 \mathrm{~cm}^{-1}\right)$ ratio; third row, aliphatic/carboxyl $\left(=2925 / 1710 \mathrm{~cm}^{-1}\right) \mathrm{ratio}$; fourth row, carboxyl/aromatica ${ }^{\mathrm{a}}\left(=1710 / 1600 \mathrm{~cm}^{-1}\right)$ ratio.

enough to leave the exine UAC content unchanged. Similarly, acetolysis should be appropriate for calibrating modern and fossil UAC concentrations. New $\mathrm{C}-\mathrm{O}$ bonds formed during acetolysis (Domínguez et al., 1998) do not affect the measurement of UAC concentrations using FTIR, because these are limited to the 1250$1000 \mathrm{~cm}^{-1}$ part of the spectrum, and therefore do not interfere with the $1510 \mathrm{~cm}^{-1}$ aromatic ${ }^{\mathrm{b}}$ peak or the $3300 \mathrm{~cm}^{-1}$ hydroxyl peak.

Oxidation with nitric acid causes the aromatic ${ }^{b}$ peak to increase in size and move to higher wavenumbers. For processing procedures using nitric acid at room temperature for a matter of minutes (e.g. Jardine et al., 2012) this is unlikely to cause problems because chemical changes are limited (Figs 2, 4 and 5). With increasing time and/or heat, however, the large shift in the position of this peak means that the measurement range will have to be increased to $c .1560 \mathrm{~cm}^{-1}$, and it may make chemical changes associated with ambient UV-B impossible to recover with FTIR spectroscopy.
Taxonomic studies are likely to focus on whole spectra (Pappas et al., 2003; Zimmermann, 2010) or a subsection of it (Dell'Anna et al., 2009). These results show that while there is an obvious chemical separation between untreated Lycopodium and angiosperm samples, as would be expected if sporomorph chemistry contains a phylogenetic signal, acetolysis tends to reduce the difference between them. The angiosperm taxa also became less chemically distinct from each other after acetolysis, plotting closer together in ordination space than the untreated samples did. This suggests that some of the chemical taxonomic signal occurs external to the exine, and the loss of these compounds reduces discriminatory power of sporomorph chemistry. The addition of C-O bonds during acetolysis (Domínguez et al., 1998) in all taxa further homogenized the FTIR spectra relative to untreated specimens, and it may be preferable to exclude these peaks from taxonomic analyses of acetolysized sporomorphs. Nevertheless, the major separation between Lycopodium and angiosperms is still 


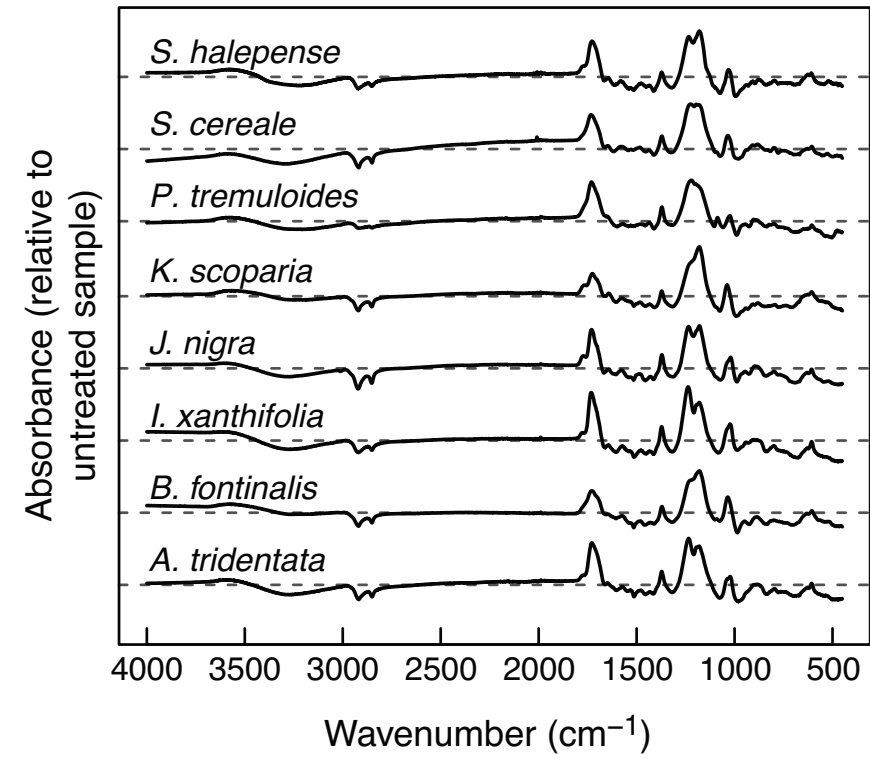

Fig. 6. Difference plots for angiosperm taxa, showing the acetolysized spectrum minus the untreated spectrum. Grey dashed line $=0$ (i.e. no difference between oxidized and untreated spectra). Samples were acetolysized at $90^{\circ} \mathrm{C}$ for $10 \mathrm{~min}$. present, suggesting that sporomorph chemistry has potential as a taxonomic tool in the fossil record.

\section{CONCLUSION}

Oxidation is commonly used in palynological processing, and here we have shown that if used carefully it does not have a detrimental effect upon sporopollenin chemistry. Acetolysis removes the protoplasm, intine and outer compounds from sporomorphs but leaves the exine relatively unchanged. While this is likely to reduce sensitivity for UV-B estimation and taxonomic differentiation compared to freshly harvested sporomorphs, it should have little or no effect on fossil sporomorphs where only the exine remains. Nitric acid is a more aggressive agent and, with sufficient time and/or heat, breaks down the exine itself. However, when used at room temperature and for limited periods the impact on sporopollenin chemistry is predictable and limited and, for this and heated acetolysis, $10 \mathrm{~min}$ is a sensible absolute maximum for treatment. Heated nitric acid should be avoided for studies of sporomorph chemistry, because this rapidly destroys the exine and fundamentally alters the chemical signal. Given the chemical differences between freshly harvested and oxidized sporomorphs, either through isolation of the exine or alterations to it, it will be important in future studies to fully document the processing
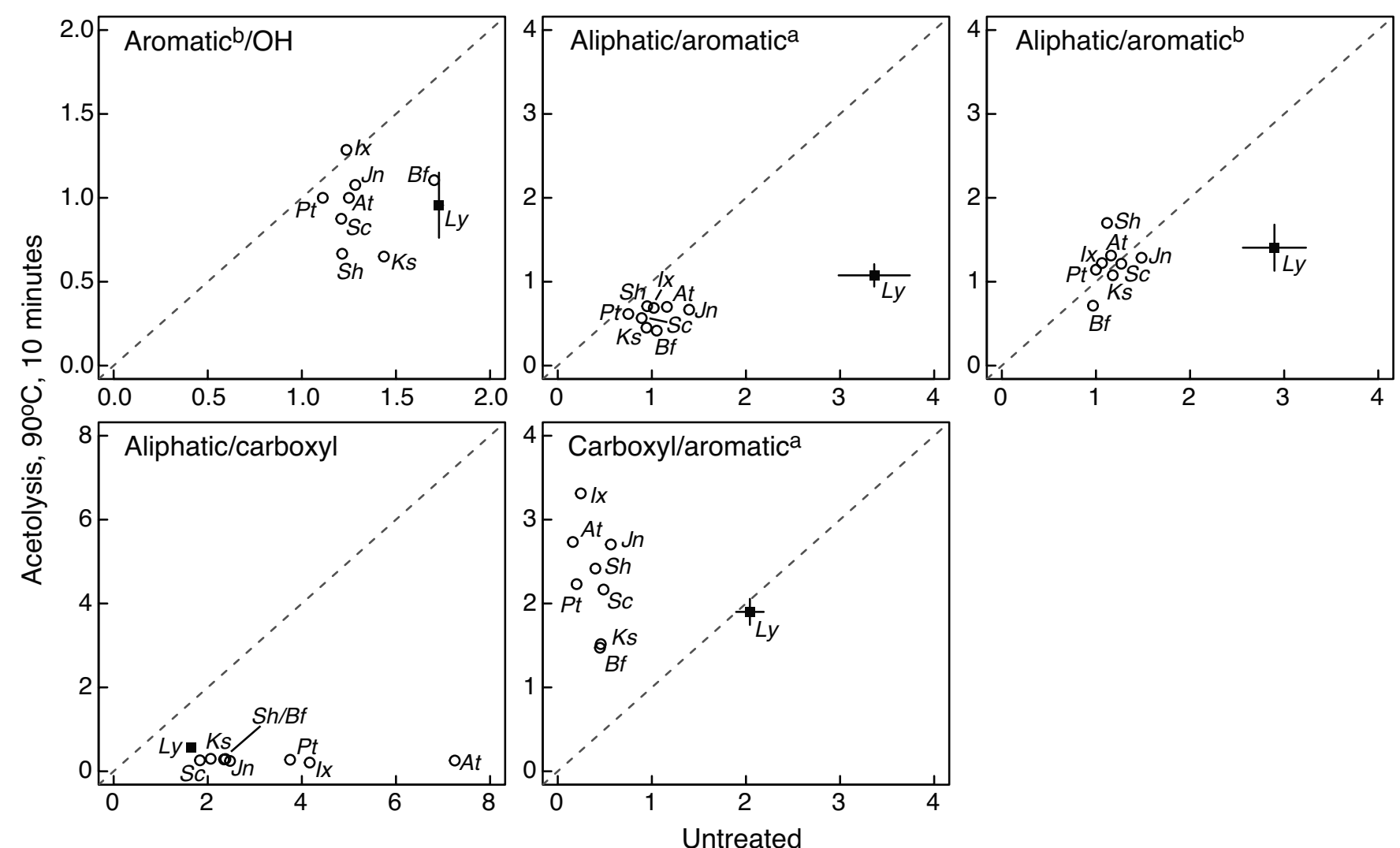

Fig. 7. Changes in peak height ratios for angiosperm taxa. Ratios for untreated samples are shown on the $x$-axis, ratios for acetolysized samples (at $90^{\circ} \mathrm{C}$ for $10 \mathrm{~min}$ ) are shown on the $y$-axis, the grey dashed line equals no difference between untreated and acetolysized samples. At, Artemisia tridentata; Bf, Betula fontinalis; Ix, Iva xanthifolia; Jn, Juglans nigra; Ks, Kochia scoparia; Pt, Populus tremuloides; Sc, Secale cereale; Sh, Sorghum halepense. Black square denotes mean acetolysized Lycopodium ratio, error bars are 1 standard deviation. 


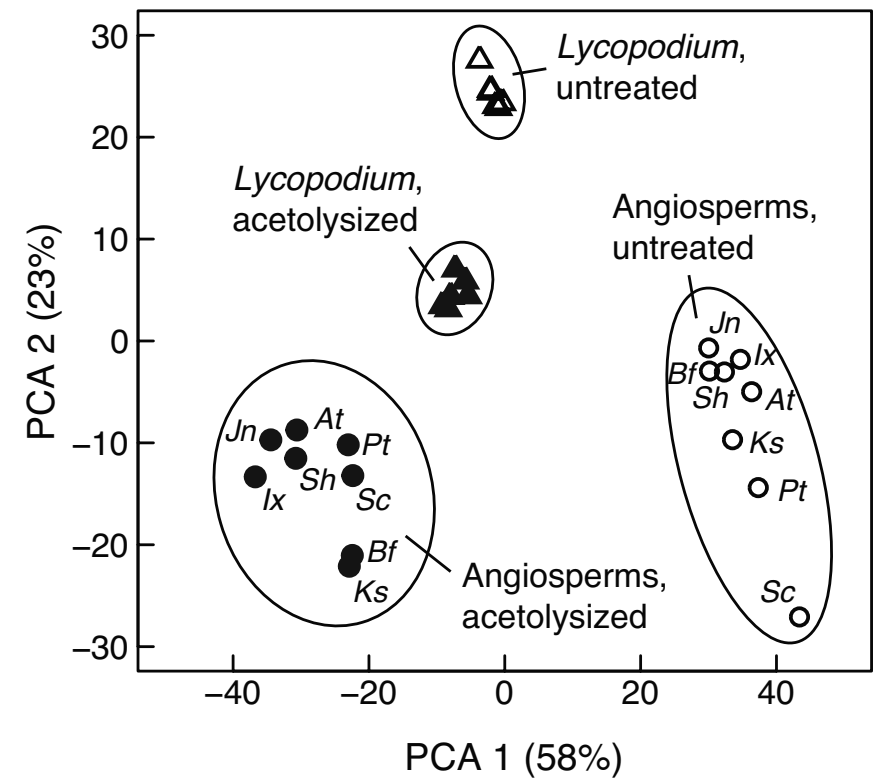

Fig. 8. Principal components analysis plot for angiosperms (circles) and Lycopodium (triangles), showing untreated samples (open symbols) and those acetolysized at $90^{\circ} \mathrm{C}$ for $10 \mathrm{~min}$ (filled symbols). Angiosperm taxon code as for Figure 7. Percentages in parentheses are the percentage of variation in the data explained by each PCA axis.

methods used, so that UV-B reconstructions and taxonomic spectra can be properly calibrated and interpreted.

\section{ACKNOWLEDGEMENTS AND FUNDING}

We thank NERC (grant NE/K005294/1) and the Royal Society (grant RG120535) for funding this research. Charles Wellman and David Jolley are thanked for their insightful reviews, and Sarah Gibbs and Martin Pearce for efficient editorial support.

\section{Manuscript received 20 August 2014 \\ Manuscript accepted 2 November 2014 \\ Scientific editing by Martin Pearce.}

\section{REFERENCES}

Ariizumi, T. \& Toriyama, K. 2011. Genetic regulation of sporopollenin synthesis and pollen exine development. Annual Review of Plant Biology, 62: 437-460.

Blokker, P., Yeloff, D., Boelen, P., Broekman, R.A. \& Rozema, J. 2005. Development of a proxy for past surface UV-B irradiation: A thermally assisted hydrolysis and methylation py-GC/MS method for the analysis of pollen and spores. Analytical Chemistry, 77: 6026-6031.

Brooks, J. \& Shaw, G. 1968. Chemical structure of the exine of pollen walls and a new function for carotenoids in nature. Nature, 219: 532533.

Brooks, J. \& Shaw, G. 1978. Sporopollenin: A review of its chemistry, palaeochemistry and geochemistry. Grana, 17: 91-97.

Dell'Anna, R., Lazzeri, P., Frisanco, M., Monti, F., Malvezzi Campeggi, F., Gottardini, E. \& Bersani, M. 2009. Pollen discrimination and classification by Fourier transform infrared (FT-IR) microspectroscopy and machine learning. Analytical and Bioanalytical Chemistry, 394: 14431452 .
Domínguez, E., Mercado, J.A., Quesada, M.A. \& Heredia, A. 1998. Isolation of intact pollen exine using anhydrous hydrogen fluoride. Grana, 37: 93-96.

Duarte, I.F., Barros, A., Almeida, C., Spraul, M. \& Gil, A.M. 2004. Multivariate analysis of NMR and FTIR data as a potential tool for the quality control of beer. Journal of Agricultural and Food Chemistry, 52: 1031-1038.

Faegri, K. \& Iversen, J. 1989. Textbook of Pollen Analysis. 4th edn. John Wiley \& Sons, New York, 328pp.

Fraser, W.T., Sephton, M.A., Watson, J.S. et al. 2011. UV-B absorbing pigments in spores: biochemical responses to shade in a high-latitude birch forest and implications for sporopollenin-based proxies of past environmental change. Polar Research, 30: 8312, http://dx.doi. org/10.3402/polar.v30i0.8312

Fraser, W.T., Scott, A.C., Forbes, A.E.S., Glasspool, I.J., Plotnick, R.E., Kenig, F. \& Lomax, B.H. 2012. Evolutionary stasis of sporopollenin biochemistry revealed by unaltered Pennsylvanian spores. New Phytologist, 196: 397-401.

Fraser, W.T., Lomax, B.H., Jardine, P.E., Gosling, W.D. \& Sephton, M.A. 2014a. Pollen and spores as a passive monitor of ultraviolet radiation. Frontiers in Ecology and Evolution, 2: 12, http://dx.doi.org/10.3389/ fevo.2014.00012

Fraser, W.T., Watson, J.S., Sephton, M.A., Lomax, B.H., Harrington, G., Gosling, W.D. \& Self, S. 2014b. Changes in spore chemistry and appearance with increasing maturity. Review of Palaeobotany and Palynology, 201: 41-46.

Gosling, W.D., Mayle, F.E., Killeen, T.J., Siles, M., Sanchez, L. \& Boreham, S. 2003. A simple and effective methodology for sampling modern pollen rain in tropical environments. The Holocene, 14: 613618.

Havinga, A.J. 1984. A 20-year experimental investigation into the differential corrosion susceptibility of pollen and spores in various soil types. Pollen et Spores, 26: 541-558.

Hemsley, A.R., Scott, A.C., Barrie, P.J. \& Chaloner, W.G. 1996. Studies of fossil and modern spore wall biomacromolecules using ${ }^{13} \mathrm{C}$ solid state NMR. Annals of Botany, 78: 83-94.

Jardine, P.E., Harrington, G.J. \& Stidham, T.A. 2012. Regional-scale spatial heterogeneity in the late Paleocene paratropical forests of the U.S. Gulf Coast. Paleobiology, 38: 15-39.

Johnson, N.G. 1985. Early Silurian palynomorphs from the Tuscarora Formation in central Pennsylvania and their paleobotanical and geological significance. Review of Palaeobotany and Palynology, 45: 307-360.

Lebreton, V., Messager, E., Marquer, L. \& Renault-Miskovsky, J. 2010. A neotaphonomic experiment in pollen oxidation and its implications for archaeopalynology. Review of Palaeobotany and Palynology, 162: 29-38.

Lieux, M.H. 1980. Acetolysis applied to microscopical honey analysis. Grana, 19: 57-61.

Lomax, B.H., Fraser, W.T., Sephton, M.A. et al. 2008. Plant spore walls as a record of long-term changes in ultraviolet-B radiation. Nature Geoscience, 1: 592-596.

Lomax, B.H., Fraser, W.T., Harrington, G., Blackmore, S., Sephton, M.A. \& Harris, N.B.W. 2012. A novel palaeoaltimetry proxy based on spore and pollen wall chemistry. Earth and Planetary Science Letters, 353354: 22-28.

Pappas, C.S., Tarantilis, P.A., Harizanis, P.C. \& Polissiou, M.G. 2003. New method for pollen identification by FT-IR spectroscopy. Applied Spectroscopy, 57: 23-27.

R Core Team. 2014. R: A language and Environment for Statistical Computing. $R$ Foundation for Statistical Computing. Vienna, Austria, http://www.R-project.org/

Rozema, J. 2002. Toward solving the UV puzzle. Science, 296: 16211622.

Rozema, J., van de Staaij, J., Björn, L.-O. \& de Bakker, N. 1999. Depletion of stratospheric ozone and solar UV-B radiation: evolution 
of land plants, UV-screens and functions of polyphenolics. In Rozema, J. (Ed.), Stratospheric Ozone Depletion: The Effects of Enhanced UV-B Radiation on Terrestrial Ecosystems. Backhuys, Leiden, 1-19.

Rozema, J., Broekman, R.A., Blokker, P. et al. 2001a. UV-B absorbance and UV-B absorbing compounds (para-coumaric acid) in pollen and sporopollenin: The perspective to track historic UV-B levels. Journal of Photochemistry and Photobiology B: Biology, 62: 108-117.

Rozema, J., Noordjik, A.J., Broekman, R.A. et al. 2001b. (Poly)phenolic compounds in pollen and spores of Antarctic plants as indicators of UV-B: A new proxy for the reconstruction of past solar UV-B? Plant Ecology, 154: 11-26.

Rubenstein, C.V., Gerriene, P., de la Puente, G.S., Astini, R.A. \& Steemans, P. 2010. Early Middle Ordovician evidence for land plants in Argentina (eastern Gondwana). New Phytologist, 188: 365-369.

Steemans, P., Lepot, K., Marshall, C.P., Le Herisse, A. \& Javaux, E.J. 2010. FTIR characterisation of the chemical composition of Silurian miospores (cryptospore and trilete spores) from Gotland, Sweden. Review of Palaeobotany and Palynology, 162: 577-590.

Traverse, A. 1988. Paleopalynology. Unwin Hyman, Massachusetts, $600 \mathrm{pp}$.
Twiddle, C.L. \& Bunting, M.J. 2010. Experimental investigations into the preservation of pollen grains: a pilot study of four pollen types. Review of Palaeobotany and Palynology, 162: 621-630.

Varmuza, K. \& Filzmoser, P. 2009. Introduction to Multivariate Statistical Analysis in Chemometrics. CRC Press, Boca Raton, 336pp.

von Post, L. 1916, reprinted 1967. Forest tree pollen in south Swedish peat bog deposits. Pollen et Spores, 9: 375-401.

Watson, J.S., Septhon, M.A., Sephton, S.V. et al. 2007. Rapid determination of spore chemistry using thermochemolysis gas chromatographymass spectrometry and micro-Fourier transform infrared spectroscopy. Photochemical and Photobiological Sciences, 6: 689-694.

Willis, K.J., Feurdean, A., Birks, H.J.B. et al. 2011. Quantification of UV-B flux through time using UV-B-absorbing compounds contained in fossil Pinus sporopollenin. New Phytologist, 192: 553-560.

Wood, G.D., Gabriel, A.M. \& Lawson, J.C. 1996. Palynological techniques - processing and microscopy. In Jansonius, J. \& McGregor, D.C. (Eds), Palynology: Principles and Applications. American Association of Stratigraphic Palynologists Foundation, Dallas, Texas, 29-50.

Zimmermann, B. 2010. Characterization of pollen by vibrational spectroscopy. Applied Spectroscopy, 64: 1364-1373. 


\section{New Publications}

To add to your bookshelf...

The

Geological

Society

serving science $\mathcal{E}$ profession

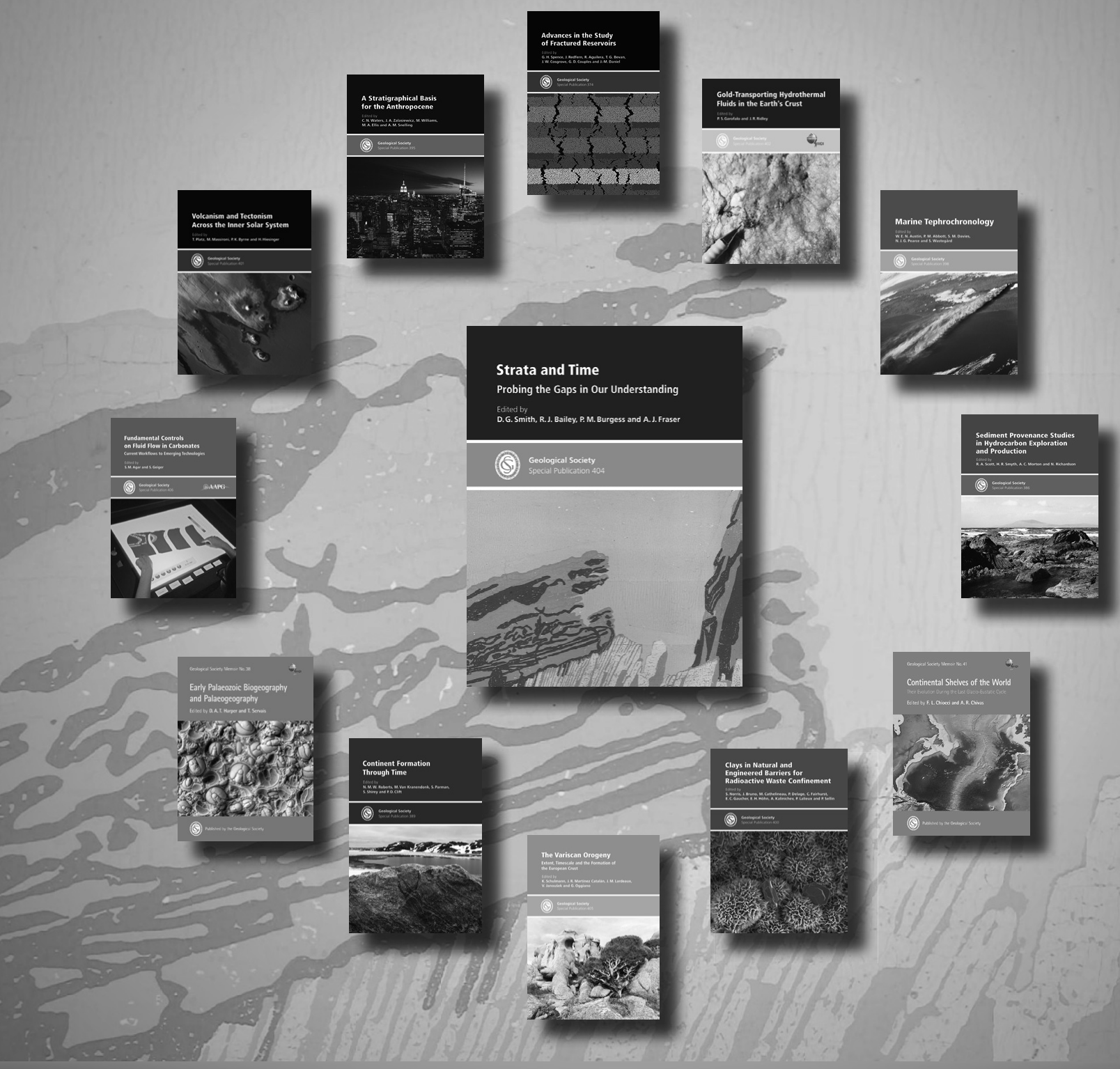

UP TO $50 \%$ DISCOUNT FOR GSL MEMBERS ON SELECTED TITLES!

Members of other societies may also qualify for discounts - contact us for details.
Browse the Online Bookshop for these and other titles from the Geological Society and other earth science publishers, visit: www.geolsoc.org.uk/bookshop 